\title{
An ataxic form of subacute presenile polioencephalopathy (Creutzfeldt-Jakob disease)
}

\author{
BETTY BROWNELL AND D. R. OPPENHEIMER \\ From the Department of Neuropathology, Radcliffe Infirmary, Oxford
}

In 1955 Foley and Denny-Brown reported three cases of subacute progressive encephalopathy occurring in middle age, and leading to death within 13 months. The outstanding clinical features, in order of appearance, were: ataxia of cerebellar type, with dysarthria; involuntary rhythmic jerking movements; dementia; stupor, progressing to coma; and finally, a state of generalized muscular rigidity, in which the involuntary movements tended to disappear.

Two of these cases were examined at necropsy. In their first case, there was a severe and widespread loss of neurones in the cerebral cortex and the granular layer of the cerebellum, with intense proliferation of astrocytes and microglia. Lesser degrees of cell loss and glial overgrowth were found in the thalamus, basal ganglia and elsewhere. Their case 3 , in which the illness was of shorter duration, showed similar but less severe lesions in the cerebral and cerebellar cortex and basal nuclei. In neither case was there any sign of vascular disease, or any significant abnormality outside the central nervous system.

In their original report, Foley and Denny-Brown (1955) described this condition as 'a cerebral disease which is so unique in its clinical manifestations that we feel justified in regarding it as a disease entity'. However, in a subsequent communication (1957) they assigned their cases to the category of 'Jakob's pseudosclerosis', that is, of what is now usually called Creutzfeldt-Jakob disease. Subsequent authors have accepted this attribution.

Since then, at least three similar cases have been recorded (Lesse, Hoefer, and Austin, 1958: case 11; Katzman, Kagan, and Zimmerman, 1961; Silberman, Cravioto, and Feigin, 1961). These were also cases of a subacute encephalopathy, occurring in middle age, fatal within 12 months, presenting with ataxia and dementia. These symptoms progressed rapidly, abnormal involuntary movements occurred, and the final state was one of profound stupor or mutism, with generalized muscular rigidity, in which the abnormal movements tended to disappear. In each of these cases there were severe changes in the cerebral cortex and the granular layer of the cere- $\frac{\bar{c}}{\bar{c}}$ bellum. In one case the thalamus, and in two the $\frac{\bar{\sigma}}{\vec{\sigma}}$ corpus striatum, were involved. There was no vascu- $\varrho$ lar pathology, and no significant disease outside the central nervous system.

These six cases, along with four which we are about to describe, seem to form a well-defined $\vec{\omega}$ clinical and pathological entity. The nature of the condition, and its relationship with the Creutzfeldt- 3 Jakob disease, will be discussed later. The clinical histories of our cases will be given first; the pathological findings will be described together.

CASE REPORTS

CASE 1 W.K., a watercress grower, was a man aged $\overline{49}$ at the time of his death in March 1960 . He was first admitted to hospital in October 1959, when he complained of numbness and tingling in his left hand, and unstea ness of his legs, gradually increasing over a period of about $\overrightarrow{0}$ four months. For about one month he had suffered $G$ occasional extensor spasms of all four limbs. There was no relevant personal or family history. The only abnorm-O alities found on examination were in the nervous system. These consisted in bilateral nystagmus, ataxia, with increased tone, in all four limbs, unsteadiness of gait, $a \%$ positive Romberg's sign, and a general impairment of ${ }_{\Omega}^{\mathbb{D}}$ sensation to pinprick. All investigations were negative $\Rightarrow$ with the exception of air encephalography, which showed $\frac{\text { O }}{3}$ slight dilatation of the lateral ventricles. Electroence- 3 phalography showed some slow activity on a fairly normal background. The E.E.G: was not repeated.

The patient was discharged home with no definite diagnosis. His condition steadily deteriorated, and by January 1960 he was mute, akinetic and doubly inconti-o nent, with spastic limbs and bilateral extensor plantar 3 responses. He died in March, about eight months after the onset of symptoms.

Post-mortem examination, which was limited to the head, was carried out 24 hours after death (R.I. pm. 을 no. 251/60). The skull, meninges, and intracranial $>$ vessels appeared normal. The immediate cause of death을 is not known.

CASE 2 A.H., a woman of 55, was seen as an out- $N$ patient in October 1962, complaining of unsteady gait N and inability to ride a bicycle. These symptoms had come ${ }^{\omega}$ 
on during the past two weeks. There was also a complaint of a 'numb feeling' in the left hand; on questioning, this appeared to consist in a lack of awareness of the hand, and a tendency to drop things held in the left hand. A further symptom was of 'things not sounding right', for instance music in church. The patient had been well up till then; the only possibly relevant item in the history was a mild head injury, with momentary loss of consciousness, eight months before. On examination she was slightly euphoric, but rational. Speech was somewhat dysarthric. She could walk unaided, but occasionally staggered. There was nystagmus, limb and trunk ataxia, and some titubation of the head. Sensation and hearing seemed intact. Electroencephalography showed reasonably well-preserved activity, with scattered slow components. Ten days later, she was admitted for further investigation. In the interval, deterioration had occurred. She was now clearly demented, euphoric, and dysphasic. There was continuous nystagmus, severe dysarthria of cerebellar type, and a grossly ataxic gait. There were also constant choreiform movements of the face and limbs. Tendon reflexes were brisk and equal, with extensor plantar responses. No sensory abnormalities were detected. Bilateral papilloedema was noted.

The patient's mental state deteriorated rapidly, and five days after admission she was mute, uncooperative, and incontinent. Lumbar puncture, right carotid angiography and air encephalography were performed, with normal findings. Repeated E.E.G. records showed progressive loss of normal activity, and increasing slow wave activity. By the beginning of December, the involuntary movements were taking the form of myoclonic jerkings; these were associated, in the E.E.G., with episodes of slow and sharp waves, occurring at intervals of one to two seconds. On the basis of this, a diagnosis of subacute spongiform encephalopathy (Nevin, McMenemey, Behrman, and Jones, 1960) was suggested. The patient remained mute, unresponsive, and twitching for about three months. A cortical biopsy in February showed severe changes, which will be described in a later section, and a diagnosis of Creutzfeldt-Jakob disease was made. During the final three months the rhythmic jerkings decreased, the limbs stiffened at first in flexion, later in extension, and generalized muscle wasting occurred. The patient died in May 1963, seven months from the onset of symptoms.

Post-mortem examination was carried out 30 hours after death (R.I. pm. no. 557/63). The immediate cause of death was bronchopneumonia. There were no other significant findings outside the central nervous system.

CASE 3 G.H., a housewife aged 47, presented in April 1964 complaining of unsteadiness in walking, 'feeling shaky', and an impression that objects moved when she looked at them. These symptoms had come on two weeks earlier, when the patient had had an infected finger. She had previously been in good health, and no further relevant history was obtained. No abnormal physical signs, nervous or otherwise, were elicited, and the complaint was thought to be psychogenic.

Two weeks later she was admitted to a psychiatric hospital. By this time she had developed weakness of the left arm, unsteadiness of the legs, and slurring of speech. On examination, she was disorientated, and had both dysphasia and dysarthria. There was an unsteady gait, and a coarse tremor of the arms, with added purposeless movements. She was not depressed, but her mental state was abnormal and she was thought to be suffering from psychogenic conversion symptoms. Over the next two days she became less responsive, and as she would not eat or drink, she became dehydrated. She was given electroconvulsive therapy (E.C.T.) once: she did not convulse, but afterwards remained unconscious for several hours. She was then admitted as an emergency to a general hospital, where after two days in a fluctuating state of consciousness, she settled into a kind of stupor. She was mute, incontinent and uncooperative, strongly resisting all passive movements and alternately restless and rigidly opisthotonic. All investigations, including lumbar puncture and air encephalography, were normal.

Ten days after the first E.C.T., the patient was readmitted to the psychiatric ward and given daily E.C.T. for eight days. This had little effect on her conscious state. She remained rigid in all her limbs, showing a generalized coarse tremor on stimulation. She also developed a fluctuating pyrexia, attributed to urinary and chest infections, which were treated with antibiotics.

Five weeks after her course of E.C.T. she was transferred to the Churchill Hospital, Oxford. By this time she was wasted, and had a generalized body rash. She was comatose, with inconstant clonic movements of the left arm and leg, occasionally involving the right arm. Electroencephalography on three occasions showed generalized slow activity, with recurring episodes of slow and sharp waves associated with abnormal movements. These episodes were more prominent on the right, the twitching movements being mainly left-sided. On this evidence, a diagnosis of Creutzfeldt-Jakob disease was suggested. Cortical biopsy was considered but before this could be done the patient died suddenly, 13 weeks after the onset of her illness.

Post-mortem examination was carried out two days after death (R.I. pm. No. 663/64). There were no significant findings outside the central nervous system.

CASE 4 F.B., a housewife aged 60 , was first seen by a neurologist on 5 March 1958, when she gave a history of difficulty in walking for about six months. For about the same time she thought her voice had been weak. On examination, she was vague and forgetful, but orientated. The cranial nerves were normal, and there was no papilloedema. There was slight dysarthria, vertical nystagmus was present, and both arms showed a gross intention tremor. In the arms and legs, tone was normal and tendon reflexes were brisk and equal; plantar reflexes were flexor. She was grossly ataxic when standing, and her gait was extremely unsteady. A lumbar puncture produced entirely normal cerebrospinal fluid, with a pressure of $180 \mathrm{~mm}$. The diagnosis was thought to be a cerebellar tumour and she was transferred to a neurosurgical unit on 29 March 1958. By that time she had become disorientated and mildly demented and was unable to stand or walk without support; other physical signs were unchanged. Air encephalography showed 
slight dilatation of the lateral ventricles, and considerable enlargement of the third ventricle, but no evidence of a space-occupying lesion. A diagnosis of cerebellar degeneration was made, and the patient was transferred to a general hospital on 4 April. By this time, mental confusion and ataxia were much worse, and feeding was difficult. Her illness progressed rapidly and she soon became helpless, incomprehensible, and doubly incontinent. On 23 May she developed athetoid movements of the left arm, and about this time her plantar reflexes were noted to be extensor. She developed a chest infection and died on 29 May 1958, about eight months after the beginning of her illness.

A post-mortem examination was carried out at Amersham General Hospital (PM. 73/58) by Dr. R. W. Harries, who kindly sent the brain to us for examination. The only findings outside the central nervous system were of bronchopneumonia, coronary atheroma, and left ventricular hypertrophy.

PATHOLOGICAL FINDINGS IN THE NERVOUS SYSTEM

In cases 2 and 3 , both of which had shown generalized muscular wasting before death, samples of peripheral nerve and muscle were examined. These showed no signs of neuropathy; muscle fibres were in general rather small in calibre, but otherwise normal.

The brain in all four cases was externally unremarkable, with healthy vessels. On section, there was slight to moderate symmetrical dilatation of the lateral ventricles, and perceptible thinning of the cortical ribbon in cases 2 and 3. No focal lesions were seen in the cerebral hemispheres. The brainstem and spinal cord appeared normal. The cerebellum showed generalized cortical atrophy (Fig. 1) with unnaturally firm white matter.

Histological changes, similar in kind but differing in degree from case to case, were observed in the grey matter of the brain and spinal cord. In each

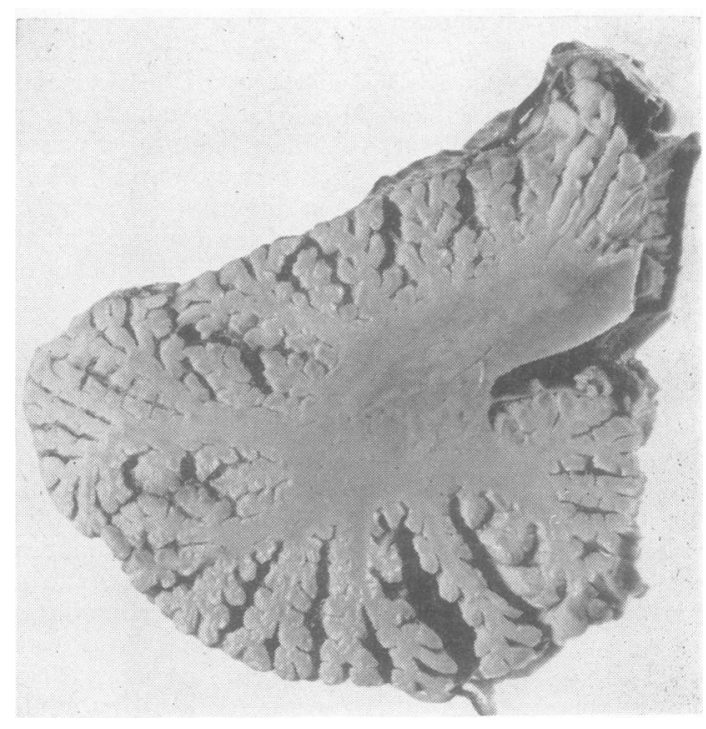

FIG. 1. Cut surface of cerebellar hemisphere, showing atrophy of cortex (case 1). $\times 1 \frac{3}{4}$.

case, the lesions appeared to be bilaterally symp metrical. They consisted in nerve cell changes ar cell loss, astrocytic and microglial proliferation, ared fibrous gliosis. There were no signs of an inflante matory or of a demyelinating process. In three case there were terminal ischaemic cell changes, but apart from this there was no evidence of vascular or $\vec{\varnothing}$ circulatory disturbance. The vessels, large and small, or appeared healthy throughout. Table I shows the relative distribution of nerve cell loss and astrocytosis in the four cases.

CHANGES IN NERVE CELLS Abnormal-looking nerve $\stackrel{\infty}{\mathbb{\Phi}}$

TABLE I

\begin{tabular}{|c|c|c|c|}
\hline \multirow{2}{*}{ Case $1(W \cdot K .)^{1}$} & \multicolumn{2}{|c|}{ Case $2(A . H .)^{1}$} & Case 3 (G.H.) \\
\hline & Cell Loss & Astrocytosis & Cell Loss \\
\hline
\end{tabular}

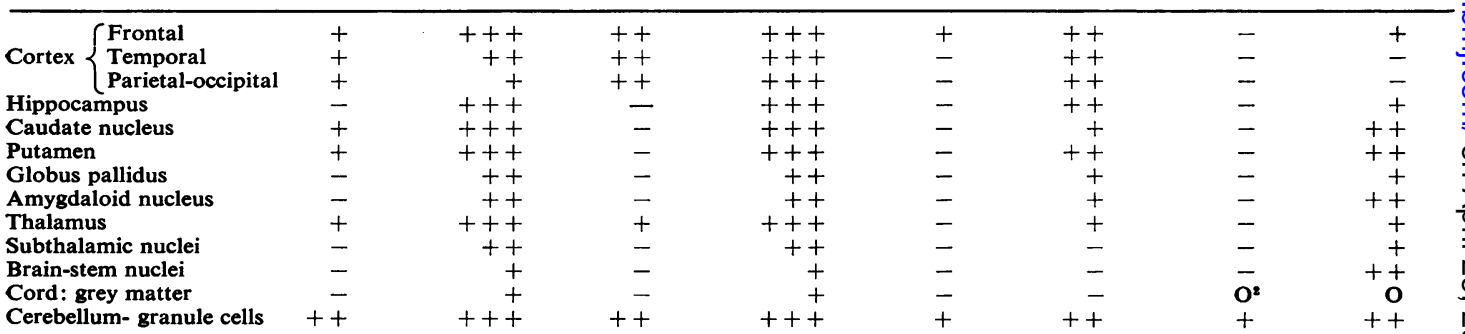

${ }^{1}$ In cases 1 and 2 , nerve cell loss in cerebral cortex, striatum, and thalamus was difficult to assess for reasons given in the text. ${ }^{2} \mathrm{O}=$ not examined. 


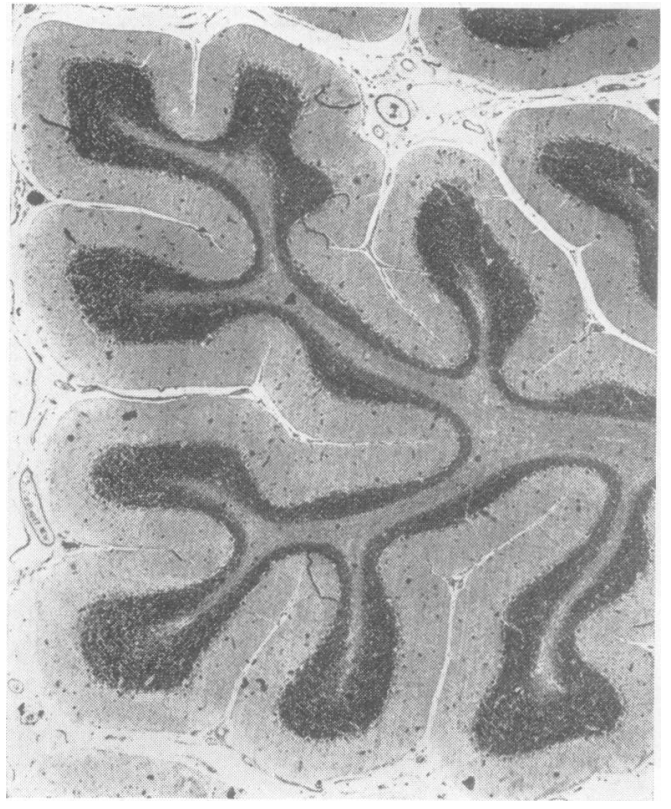

FIG. 4.

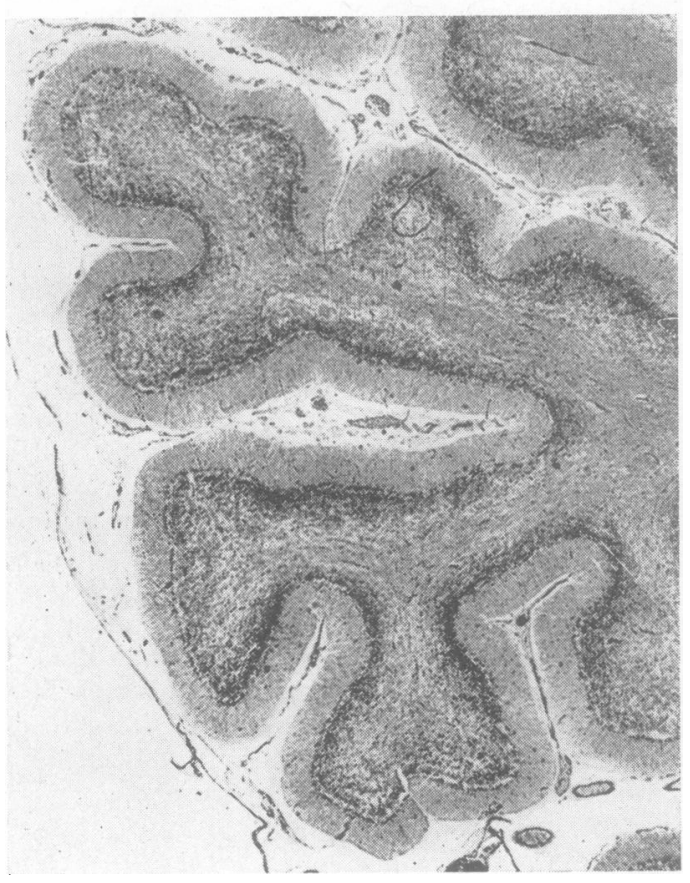

FIG. 6 . 


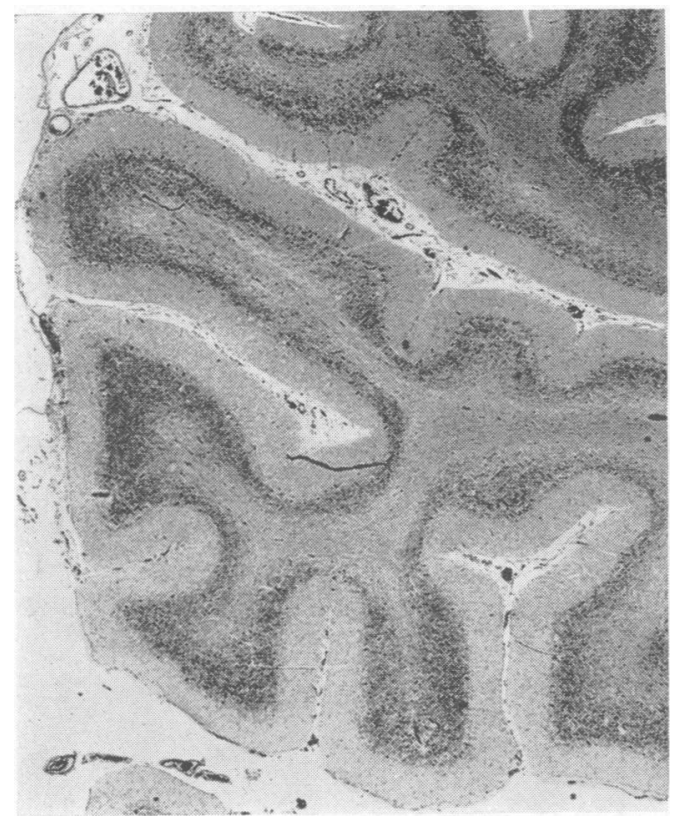

FIG. 8. Cerebellar cortex in case 4. $10 \mu$ section. Haematoxylin and eosin $\times 15$. (See page 354 .)

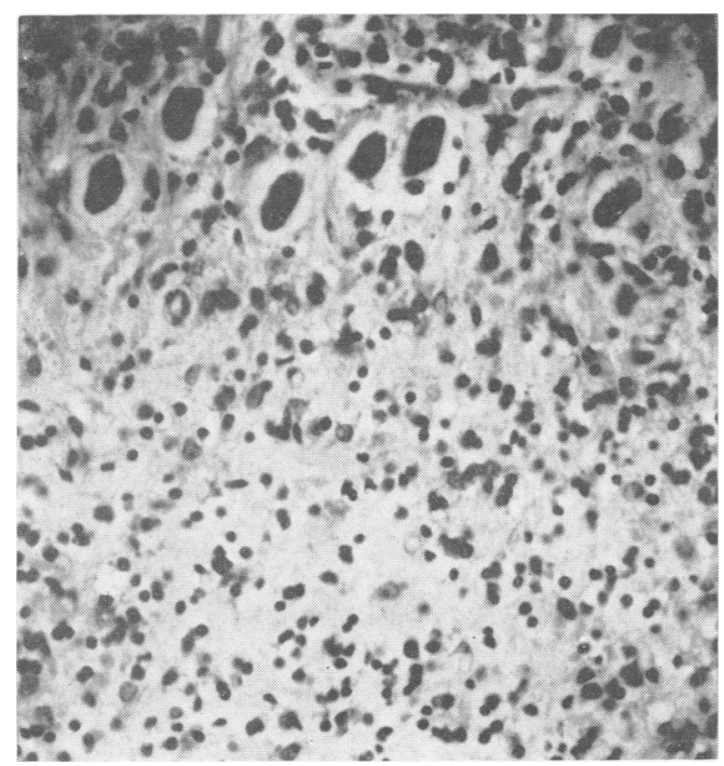

FIG. 9. Cerebellar cortex, showing rarefaction of granule cells, and pyknosis of many remaining cells (case 3). There are numerous large astrocytic nuclei. Nissl $20 \mu, \times 275$.

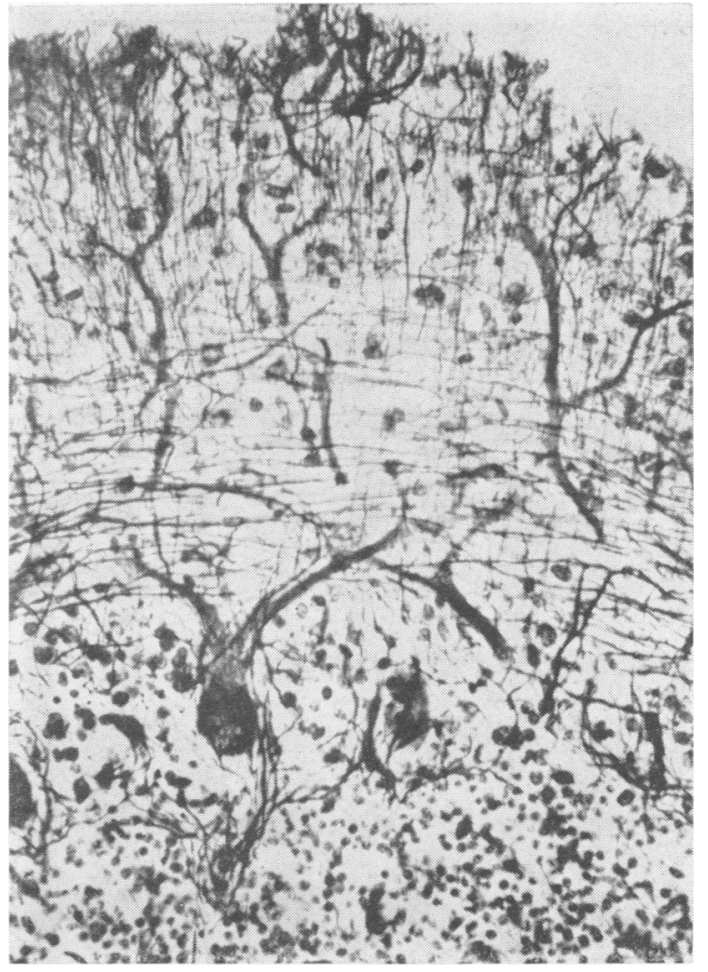

FIG. 10. Thickening and terminal sprouting of Purkinje cell dendrites (case 3). Basket fibres are prominent. Cajal's silver-pyridine method, $\times 225$.

'torpedoes'. The basket fibres also appeared thickened, including the pericytial baskets.

ASTROCYTIC HYPERPLASIA In general, this was present in grey matter, in the immediately subcortical white matter, and throughout the cerebellum. In case 1,2 , and 4 , a mild astrocytosis, with fibrillar gliosis, was present in the grey matter of the whole central nervous system, and was seen in the brainstem and spinal cord in the absence of any other detectable changes (Fig. 11). It was most intense in the cerebral and cerebellar cortex, striatum, and thalamus. There was no clear relationship between astrocytosis and nerve cell loss; for instance, in the hippocampus, where no cell loss was seen, there was in three cases a dense astrocytosis (Fig. 12). For the most part, the proliferated cells were mediumsized fibrous astrocytes. In cases 1 and 2, there were numerous large, sometimes binucleate, gemistocytic types in the cerebral cortex; and in case 1 , the putamen was densely populated by cells of this type (Fig. 13). Protoplasmic forms, mixed with fibrous and intermediate types, were seen in the caudate nucleus and hippocampus in case 3 (Fig. 14). 


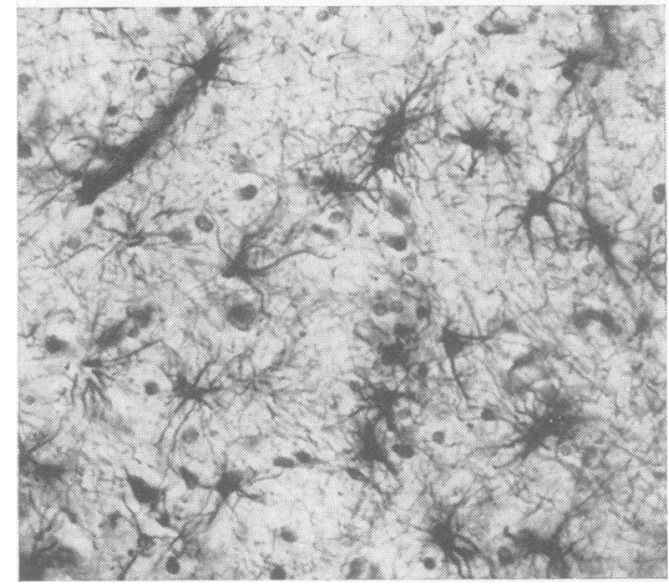

FIG. 11. Proliferated astrocytes in reticular formation of medulla (case 2). Holzer, $\times 245$.

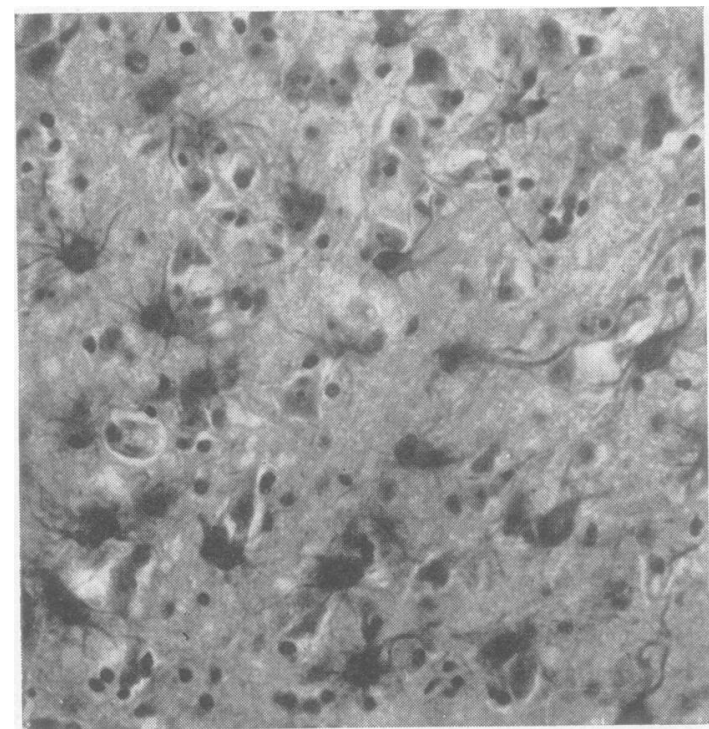

FIG. 12. Hippocampus, showing well-preserved pyramidal nerve cells mixed with large proliferated astrocytes (case 1). Phosphotungstic acid/haematoxylin, $\times 265$.

Clasmatodendrosis was seen only occasionally. In a given region, the density of the astrocyte population was very even. It appeared the same throughout the thalamus, and there was no trace of laminar distribution in the cerebral cortex (Fig. 15). Apart from the immediately subcortical strip, the white matter was unaffected, including even the small myelinated bundles in the putamen (Fig. 16).

FIBROUS GLIOSIS There was an abnormal degree of subpial and subependymal gliosis throughout the

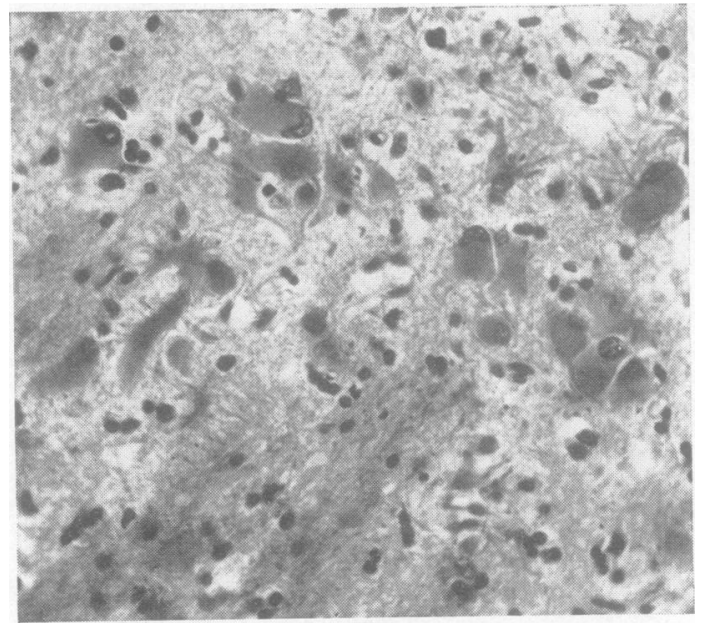

FIG. 13. Putamen, showing bizare gemistocytic cells (case 1). Phosphotungstic acid/haematoxylin, $\times 240$.

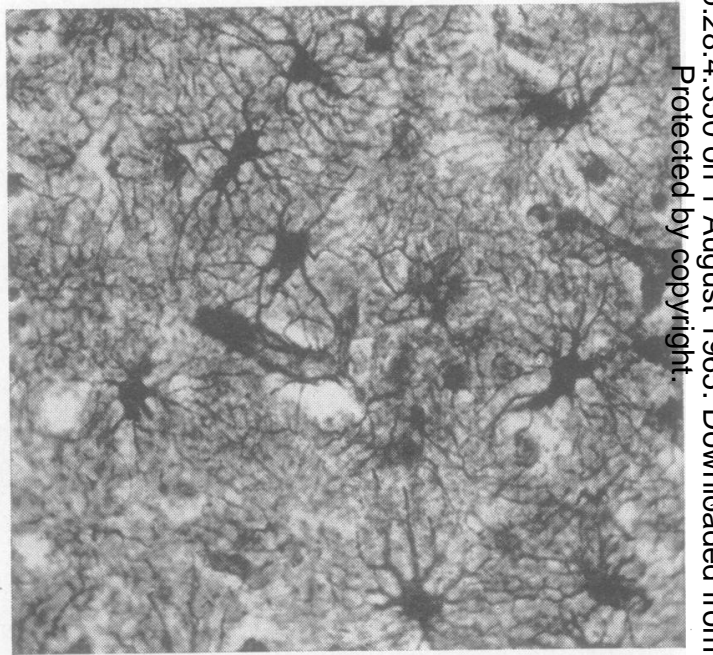

FIG. 14. Protoplasmic astrocytes in temporal cortex (case 3). Cajal's gold sublimate, $\times 275$.

brain in every case, apparently unrelated to the severity of the changes in underlying tissues. The Bergmann glia was proliferated, with intense isomorphous gliosis of the molecular layer (Fig. 17).

MICROGLIAL PROLIFERATION Active forms of microglia were conspicuous in the cerebral cortex, hippocampus, and molecular layer of the cerebellum $N$ (Figs. 18 and 19). They were least conspicuous in case 3. Compound granular corpuscles were not seen. 

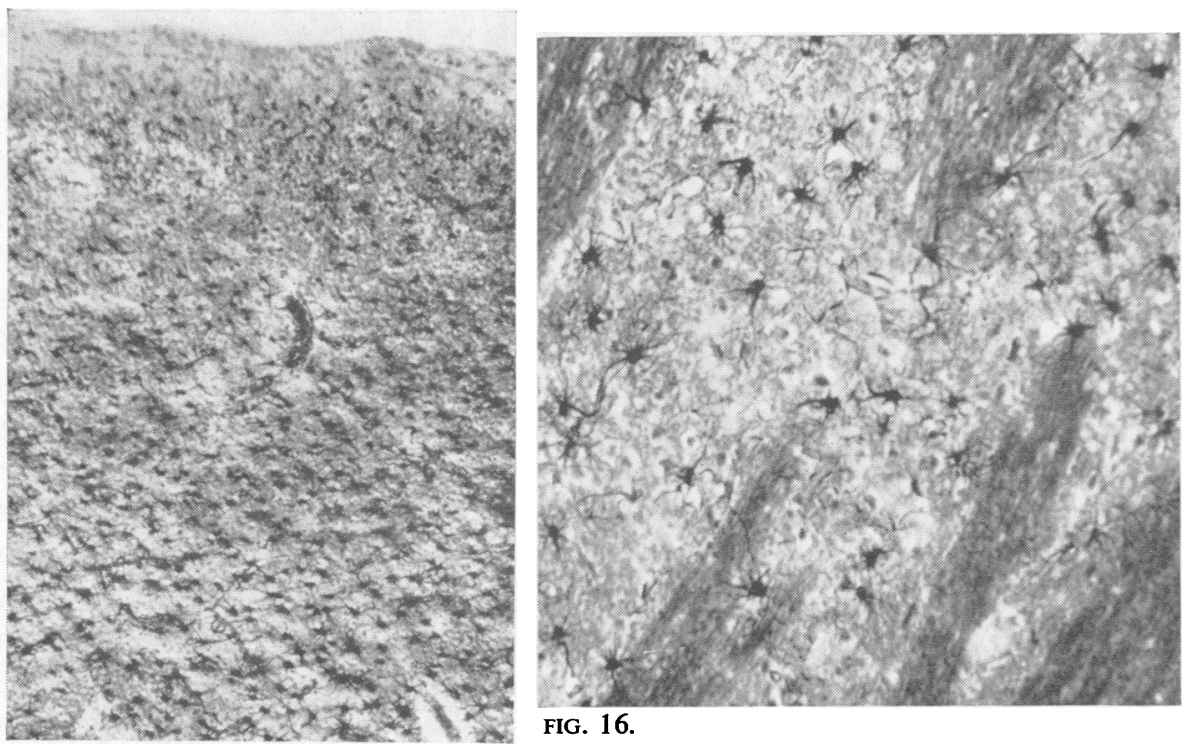

FIG. 15. Fibrous

astrocytes in

temporal cortex

(case 2). Cajal's

gold sublimate,

$\times 52$.

FIG. 16. Putamen, showing astrocytes in the grey matter but not in the myelinated bundles (case 3). Cajal's gold sublimate, $\times 125$.

FIG. 16

FIG. 15.

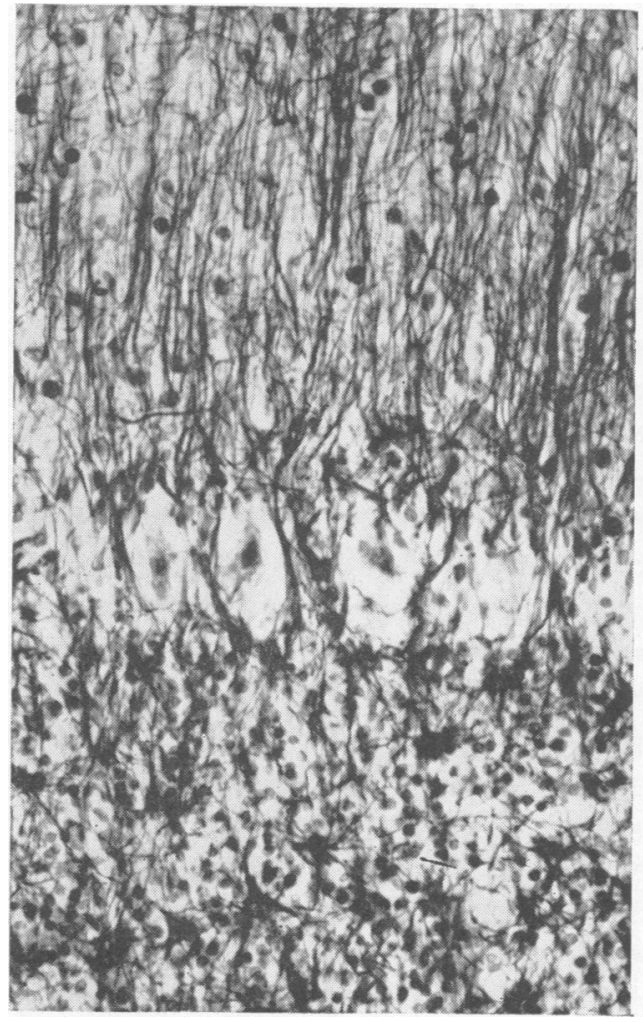

FIG. 17. Bergmann glia in molecular layer (above) and fibrous astrocytes in granular layer (below) in case 2 . Holzer, $\times 280$.
OTHER CHANGES Status spongiosus, not very striking in degree, was seen in some areas of cerebral cortex in cases 1, 2, and 4 (Fig. 20). Sudanophil lipid was not seen, except as a fine extracellular dust in the lentiform nucleus and internal capsule in case 1. The only changes seen in white matter were a pallor of myelin in the centrum ovale in case 2 (Fig. 3 ), and slight pallor of the corticofugal tracts in cases 1 and 2. Vessels, meninges, ependyma, and choroid plexus were unremarkable. Argyrophilic plaques and neurofibrillary tangles were not seen.

\section{DISCUSSION}

The clinical picture in these four cases, together with the six cases referred to in the introduction, is remarkably uniform. The patients were two men and eight women aged between 40 and 60 . The disease presented as a rapidly progressing ataxia (sometimes preceded by vague sensory disturbances), followed by progressive dementia and the appearance of involuntary movements, often in the form of rhythmic 'myoclonic' jerkings. In the final state, speech was totally lost, and the abnormal movements tended to be lost in a state of generalized muscular rigidity. The duration of the disease lay between two and a half and 13 months, with a mean of seven and a half months. In cases with myoclonus which were investigated by E.E.G., there was a fairly characteristic electrical accompaniment to the abnormal movements, without features of epilepsy. In no case was the disease familial. The clinical features are summarized in Table II. 


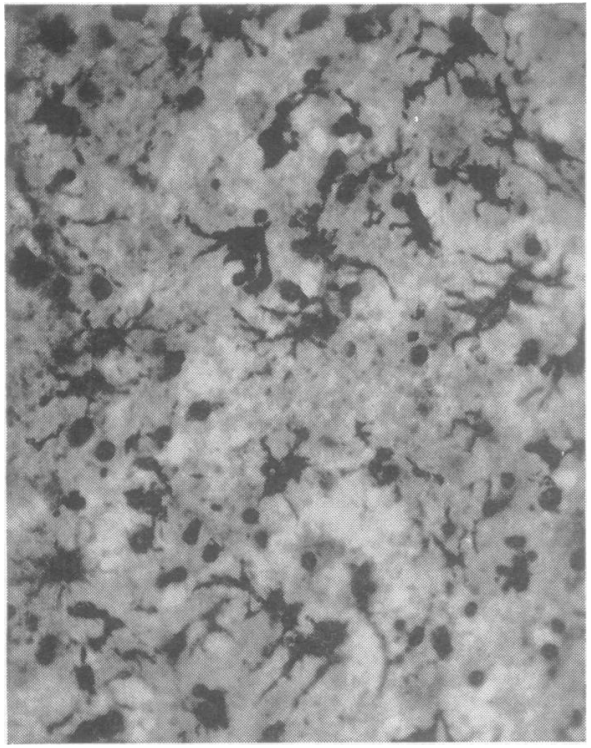

FIG. 18. Active forms of microglia in temporal cortex (case 2). Weil-Davenport, $\times 255$.

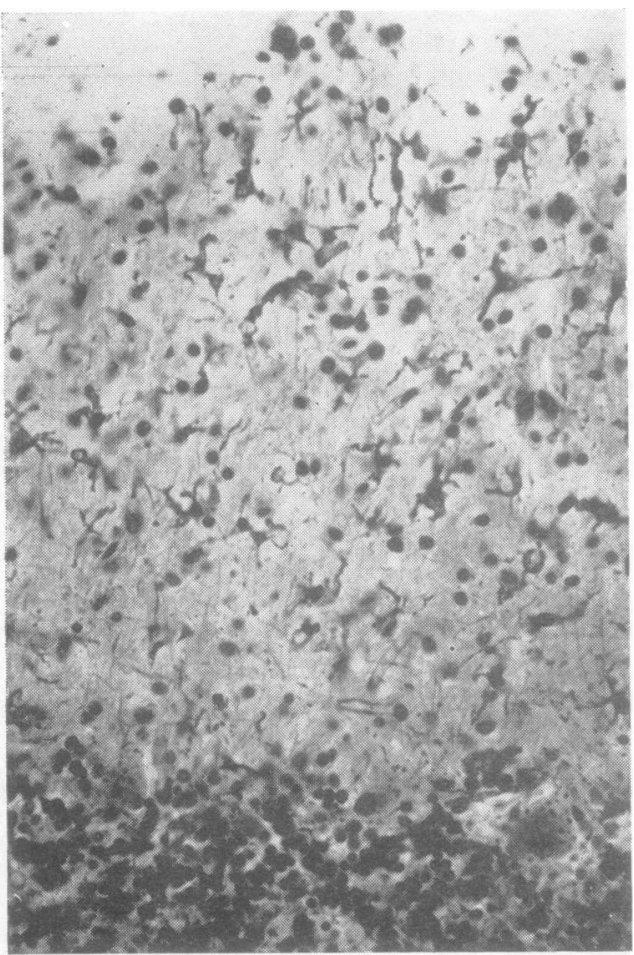

FIG. 19. Microglia in molecular layer (case 3). Weil-Davenport, $\times 225$.

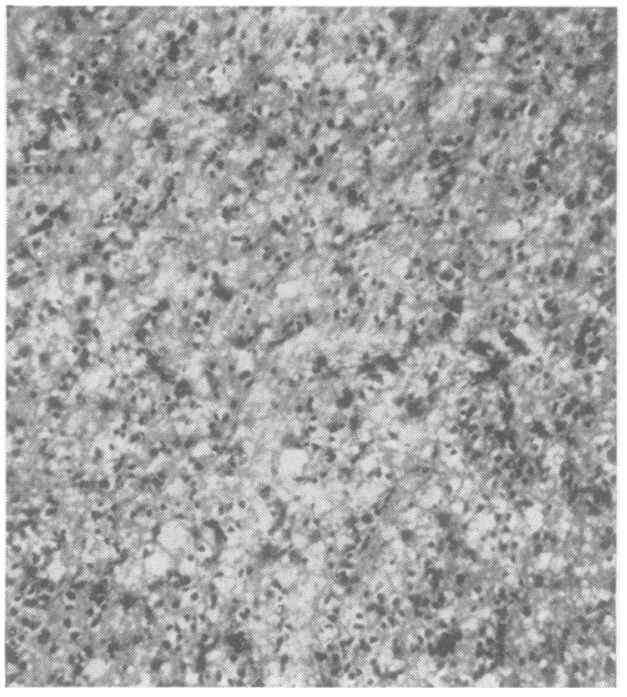

FIG. 20. Status spongiosus in frontal cortex (case 1). Phosphotungstic acid/haematoxylin, $\times 105$.

In the nine cases examined after death, the finding have been of glial proliferation in the cerebrif of cortex, with varying degrees of nerve cell loss; 1 응 all but two, there have been similar changes in the thalamus and striatum; and there has been a selee tive loss of granule cells in the cerebellar cortex. No significant changes have been seen outside the central nervous system, and there has been no sigif $\overrightarrow{0}$ of cerebral vascular disease.

If it is conceded that these 10 cases form a homo- $?$ geneous group, the question arises whether they should be placed within the larger group known as the Creutzfeldt-Jakob disease. The answer will depend on whether one regards this disease as $a_{\varrho}$ pathological entity, or as a heterogeneous collection $\stackrel{\square}{\triangle}$ of presenile cerebral degenerations.

The confusion that has arisen over this group of $\frac{0}{3}$ diseases has been considerably reduced in the past $\bar{F}$ few years by the appearance of several monographso and reviews, of which the most important are those of Alema' and Bignami (1959), Khochneviss (1960), and Siedler and Malamud (1963). These authors:consider between 60 and 70 cases in the literature; 3 . and although they do not always agree about which cases should and which should not be included, they all come to the conclusion that a definite and recog-o nizable disease entity exists, having the following characteristics:

1 CLINICAL The disease attacks men and women, $\bar{N}$ mostly between the ages of 40 and 60 , with noapparent provocation, and leads to death in a matter of months. The neurological disorders are multiple, $\omega$ 
TABLE II

CLINICAL FINDINGS IN 10 CASES

\begin{tabular}{|c|c|c|c|c|c|c|c|c|c|c|}
\hline & \multicolumn{10}{|l|}{ Case } \\
\hline & $\begin{array}{l}\text { Foley and } \\
\text { Denny- } \\
\text { Brown } \\
(\text { i955) } \\
\text { (case 1) }\end{array}$ & $\begin{array}{l}\text { Foley and } \\
\text { Denny- } \\
\text { Brown } \\
(1955) \\
\text { (case 2) }\end{array}$ & $\begin{array}{l}\text { Foley and } \\
\text { Denny- } \\
\text { Brown } \\
\text { (1955) } \\
\text { (case 3) }\end{array}$ & $\begin{array}{l}\text { Lesse et al. } \\
(1958) \\
(\text { case 11) }\end{array}$ & $\begin{array}{l}\text { Katzman } \\
\text { et al. } \\
(1961)\end{array}$ & $\begin{array}{l}\text { Silberman } \\
\text { et al. } \\
\text { (196I) } \\
\text { (case 3) }\end{array}$ & $\begin{array}{l}\text { Our } \\
\text { Case I } \\
(W . K .)\end{array}$ & $\begin{array}{l}\text { Our } \\
\text { Case } 2 \\
(\text { A.H. })\end{array}$ & $\begin{array}{l}\text { Our } \\
\text { Case } 3 \\
\text { (G.H.) }\end{array}$ & $\begin{array}{l}\text { Our } \\
\text { Case } 4 \\
(\text { F.B. })\end{array}$ \\
\hline Sex & $\mathbf{M}$ & $\mathrm{F}$ & $\mathbf{F}$ & $\mathbf{F}$ & $\mathbf{F}$ & $\mathbf{F}$ & $\mathbf{M}$ & $\mathbf{F}$ & $\mathbf{F}$ & $\mathbf{F}$ \\
\hline Age at onset & 41 & 56 & 47 & 47 & 58 & 52 & 49 & 55 & 47 & 60 \\
\hline Duration (months) & 13 & 8 & 5 & 10 & 7 & 6 & 8 & 7 & $2 \frac{1}{2}$ & 8 \\
\hline Sensory disturbance & - & - & - & + & + & - & + & + & + & - \\
\hline Ataxia/dysarthria & + & + & + & + & + & + & + & + & + & + \\
\hline Involuntary movements & + & + & + & + & + & + & + & + & + & + \\
\hline Dementia & + & + & + & + & + & + & + & + & + & + \\
\hline Mutism/stupor & + & + & + & + & + & + & + & + & + & - \\
\hline Rigidity/hypertonia & + & + & + & + & + & + & + & + & + & - \\
\hline Abnormal E.E.G. & + & + & + & + & + & + & - & + & + & - \\
\hline
\end{tabular}

and form a selection, in varying proportions, of the following: dementia, dysphasia, 'cortical' blindness, disturbances of tone and of voluntary movement, involuntary movements (often 'myoclonic' in type), ataxia, dysarthria, mutism, and amyotrophy. The cerebrospinal fluid is normal, and air encephalography shows, at the most, a mild cerebral atrophy. When myoclonus is present, there are characteristic abnormalities in the electroencephalogram (see Lesse et al., 1958: Alema' and Bignami, 1959).

2 PATHOLOGICAL The naked-eye appearance of the brain is unremarkable, though there is commonly a slight cerebral atrophy. Microscopic lesions, of varying severity, are found in a selection of the following sites: cerebral cortex, striatum (rarely pallidum), thalamus, cerebellar cortex, dentate nuclei, and motor nuclei of the brain-stem and spinal cord. The lesions consist in nerve cell changes, cell loss, glial proliferation, and sometimes status spongiosus. White matter is involved only secondarily as a result of neurone loss. (The pyramidal tracts are a possible exception to this rule. They are often found to be degenerate, especially in cases with amyotrophy.) The cerebral vessels appear healthy, or, if vascular disease is present, it appears to be incidental to the main findings. Outside the nervous system, there are no constant pathological features. The classical changes of Alzheimer's disease (argyrophilic plaques and neurofibrillary tangles) and of Pick's disease (massive atrophy of cortex and white matter in circumscribed regions, the so-called Pick cells) are not found.

This combination of clinical and pathological features, according to the reviewers, is distinctive enough to justify the view that the CreutzfeldtJakob disease is a recognizable entity rather than an amorphous collection of presenile encephalopathies. As with other diseases of unknown aetiology, a number of cases are to be found in the literature whose inclusion in the group is debatable. In particular, there is a group, clinically similar, but with pathological evidence of circulatory disturbance in the brain, often combined with status spongiosus and other features of the Creutzfeldt-Jakob disease. Khochneviss (1960) places these in a separate category of 'subacute spongiform encephalopathy', a term introduced by Jacob, Eicke, and Orthner in 1958 , leaving open the question whether the vascular pathology in such cases is the principal cause of the cerebral changes, or a secondary effect of the patient's terminal state, or a mere coincidence. This dispute remains unsettled. We only wish to remark that the existence of difficult, or 'mixed', cases of this type does not detract from the concept of CreutzfeldtJakob disease as a clinico-pathological entity, in which vascular changes are usually not demonstrable; and that the pathogenesis of status spongiosus, which has repeatedly been observed in cases belonging to the main group, has as yet not been conclusively explained. Meanwhile, this feature cannot be taken as clear evidence of a vascular or circulatory disturbance. Another important, but hitherto unanswered, question concerns the relation between Creutzfeldt-Jakob disease and motor neurone disease. About 12 cases have now been recorded, in which the clinical and pathological findings have been those of both conditions. This combination can hardly be regarded as a coincidence.

Regarding nomenclature, the term 'CreutzfeldtJakob disease' is one liable to cause confusion. As defined above, the disease is one of middle age; of 64 cases reviewed by Khochneviss (1960), threequarters lay between the ages of 40 and 60 , and seven- 
eighths between 35 and 65 . Creutzfeldt's case report (1920) was of a woman of 23. The clinical course was untypical, as it included a period of remission, and ended in status epilepticus. The brain showed uncharacteristic focal lesions, visible to the naked eye, and affecting the depths rather than the crowns of the convolutions, a feature more suggestive of anoxia or hypoglycaemia than of a primary cortical degeneration. It is doubtful whether Creutzfeldt's name would have been associated with this disease had not Jakob (1921) assimilated Creutzfeldt's case to his own. If the name 'Creutzfeldt-Jakob disease' is to be preserved, it should be understood that Creutzfeldt's paper is in no way a 'classical' description, and that Jakob's contribution does not give an adequate picture of the limits of variation of the disease. On the whole, a term such as 'subacute presenile polioencephalopathy', though less attractive, would probably cause less misunderstanding.

Whatever name is preferred for the condition, we would regard our four cases, and the six with which we have compared them, as falling well within the limits of definition given above. The common feature distinguishing these cases from most of the group is that cerebellar ataxia was a prominent early feature of the disease, and that all of them showed a selective degeneration of the cerebellar granule cells. It has been pointed out that this disease, in general, affects a selection of a limited number of grey centres, with varying degrees of severity; the result is a varying clinical picture, with a selection of a limited number of neurological disturbances. It follows from this that any subdivision of the group as a whole into clinical and pathological. 'types' is bound to be somewhat arbitrary, as the types will overlap. Thus, all our cases can be regarded as belonging to an ataxic type of the disease; but if, as Alema' and Bignami (1959) do, one wishes to distinguish a myoclonic type, some of these cases are included, others not. The point we wish to stress is that the cerebellar cortex is one of the structures at risk, and deserves to be included with the more familiar sites involved in this disease, the cerebral cortex, the striatum, the thalamus, and the motor nuclei.

Our case 4 raises an interesting problem. It is maintained that in an individual case of CreutzfeldtJakob disease, only a selection of the structures at risk are involved, the rest being affected slightly or not at all. At the same time, severe progressive dementia, and pathological changes in the cerebral cortex, are generally regarded as essential features of the disease. But there is no obvious reason why, in this variable condition, varieties should not occur in which the cerebral cortex remains more or less intact. In our case 4, the cortical lesions are slight, and consist in moderate glial hyperplasia, without demon- strable nerve cell loss, and some status spongiosus. $\mathbb{D}$ Were it not for the obvious linkage with our othero three cases, the diagnosis of Creutzfeldt-Jakob disease would be difficult to maintain. In fact, theo original pathological diagnosis in this case was of primary cerebellar degeneration. It is possible that true cases of Creutzfeldt-Jakob disease are frequently. missed, merely because of the absence of severe cerebral cortical involvement.

Some of the histological features of our cases haves a bearing on the question of pathogenesis. There iso an old and widely-held theory that this is a primaryo degenerative disease of neurones, in which gliaks hyperplasia is secondary to nerve cell loss. In ourd material, this view is compatible with the findingso in the cerebellar cortex, but quite unacceptable in ${ }^{\infty}$ regard to the cerebral changes. In all four, the glialo hyperplasia in the cortex (especially the hippo- $\overrightarrow{-}$ campus), the thalamus, and the striatum are clearly ${ }_{\infty}^{\omega}$ out of proportion to cell loss, which in most cases is not demonstrable. The theory that the primary? damage is to glial cells, and only indirectly to nervei cells, was proposed by Foley and Denny-Brown in 1957, and seconded by Silberman and colleagues jic 1961. Here, again, our material offers no suppoit. There are at present no accepted criteria (excee possibly clasmatodendrosis) for recognizing $\mathrm{a}-$ diseased or degenerate astrocyte. Clasmatodendrosis? was not a conspicuous feature in our cases; what \&eo

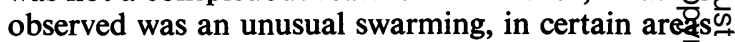
of grey matter, of healthy-looking astrocytes. The⿳亠े $\vec{\bullet}$

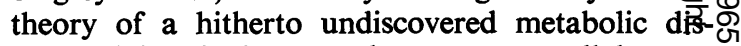
order, giving rise in some places to nerve cell destruction and in others to glial hyperplasia, would seemo to be better worth pursuing, as it is capable of investigation by the methods of tissue chemistry and enzyme histochemistry. A start was made $\frac{\square}{\square}$ with the former method by Korey, Katzman, and $\varrho$ Orloff in 1961.

Diagnosis of the condition during life should be 3 possible, in most cases, on clinical grounds alone. For this, the generalizations which emerge from the recent reviews, covering 60 or so cases, are likely to be more helpful than the single case reports of the earlier authors. Among diagnostic aids, electro- encephalography and cortical biopsy are probably the most valuable. The diagnosis of Creutzfeldt-o Jakob disease was suggested during life in cases $2 \gtreqless$ and 3 on the basis of the E.E.G., and in case 2 waso confirmed by cortical biopsy.

The condition which we have been describingo would be regarded by many neurologists as a rare variety of a rare disease. We should like to pointo out that these four cases presented at a single 0 neurological centre, and came to necropsy, within a N space of six years. 


\section{SUMMARY}

Four cases are described of a subacute encephalopathy of middle age, presenting initially with ataxia, later with dementia, abnormal movements and stupor, leading to death in a few months. Pathological changes, similar in kind but differing in degree, were found in the cerebral cortex, striatum, and thalamus; in particular, all showed a selective cell loss in the granular layer of the cerebellum. Six similar cases from the literature are quoted. We regard these 10 cases as forming part of a larger group, suffering from what is generally known as Creutzfeldt-Jakob disease, for which we prefer the term subacute presenile polioencephalopathy. Some comments are made on the pathology and diagnosis of this condition.

We wish to thank Dr. Ritchie Russell, Mr. Joe Pennybacker, and Dr. John Kidd for permission to discuss patients under their care. We are grateful to Dr. Elman Poole and Dr. Charles Whitty for their helpful comments and advice. For the photography, we are indebted to Mr. E. L. Tugwell and Dr. T. M. Parry.

Dr. Betty Brownell is in receipt of a grant from the National Fund for Research into Poliomyelitis and Other Crippling Diseases.
REFERENCES

Alema', G., and Bignami, A. (1959). Polioencefalopatia degenerativa subacuta del presenio con stupore acinetica e rigidita decorticata con mioclonie. Riv. sper. Freniat., 83, 1485-1623.

Creutzfeldt, H. G. (1920). Über eine eigenartige herdförmige Erkrankung des Zentralnervensystems. Z. ges. Neurol. Psychiat., (Orig.), 57, 1-18.

Foley, J. M., and Denny-Brown, D. (1955). Subacute progressive encephalopathy with bulbar myoclonus. Excerpta med. (Amst.), Sect. VIII, 8, 782-784.

- (1957). Subacute progressive encephalopathy with bulbar myoclonus. J. Neuropath. exp. Neurol., 16, 133-136.

Friede, R. L. (1963). Cerebellar edema. Arch. Neurol. (Chic.), 8, 67-81.

Jacob, H., Eicke, W., and Orthner, H. (1958). Zur Klinik und Neuropathologie der subakuten präsenilen spongiösen Atrophien mit diskinetischem Endstadium. Dtsch. Z. Nervenheilk., 178, 330-357.

Jakob, A. (1921). Ủber eigenartige Erkrankungen des Zentralnervensystems mit bemerkenswerten anatomischen Befunde. $Z$. ges. Neurol. Psychiat., (Orig.), 64, 147-228.

Katzman, R., Kagan, E. H., and Zimmerman, H. M. (1961). A case of Jakob-Creutzfeldt disease. J. Neuropath. exp. Neurol., 20, 78-94.

Khochneviss, A-A. (1960). Contribution à l'étude du Syndrome de Creutzfeldt-Jacob. M.D. Thesis, Éditions A.G.E.M.P., Paris.

Korey, S. R., Katzman, R., and Orloff, J. (1961). A case of JakobCreutzfeldt disease. J. Neuropath. exp. Neurol., 20, 95-104.

Lesse, S., Hoefer, P. F. A., and Austin, J. H. (1958). The electroencephalogram in diffuse encephalopathies. Arch. Neurol. Psychiat. (Chic.), 79, 359-375.

Nevin, S., McMenemey, W. H., Behrman, S., and Jones, D. P. (1960). Subacute spongiform encephalopathy. Brain, 83, 519-564.

Siedler, H., and Malamud, N. (1963). Creutzfeldt-Jakob's disease. J. Neuropath. exp. Neurol., 22, 381-402.

Silberman, J., Cravioto, H., and Feigin, I. (1961). Cortico-striatal degeneration of the Creutzfeldt-Jakob type. Ibid., 20, 105-118. 